University of Wollongong

Research Online

Australian Institute for Innovative Materials -

Papers

Australian Institute for Innovative Materials

January 2015

\title{
Thermal and electromechanical properties of melilite-type piezoelectric single crystals
}

Chuanying Shen

Shandong University

Shujun Zhang

Pennsylvania State University, shujun@uow.edu.au

Wenwu Cao

Pennsylvania State University

Hengjiang Cong

Shandong University

Haohai Yu

Shandong University

See next page for additional authors

Follow this and additional works at: https://ro.uow.edu.au/aiimpapers

Research Online is the open access institutional repository for the University of Wollongong. For further information contact the UOW Library: research-pubs@uow.edu.au 


\title{
Thermal and electromechanical properties of melilite-type piezoelectric single crystals
}

\author{
Abstract \\ Melilite-type crystals, including Ca2Ga2SiO7, Ca2MgSi207, and CaNdGa307, were successfully grown by \\ the Czochralski technique. Thermal properties were investigated and full matrices of electromechanical \\ constants of these melilite crystals were evaluated by impedance method, with d14 being on the order of \\ 5.3-9.3 pC/N. The relationship between microstructure and electromechanical properties of the three \\ kinds of crystals was established, in order to explore the piezoelectric origin and further optimize the \\ piezoelectric properties. The distortion of eight-fold antiprisms and the distortion/rotation of tetrahedrons \\ were thought to contribute to the piezoelectric d14 and d36, respectively. In addition, the layered structure \\ leads to strong anisotropic behavior, accounts for the high resistivity along Z direction in Ca2MgSi207, \\ while the disordered structure accounts for the degraded resistivity in $\mathrm{CaNdGa307.} \mathrm{The} \mathrm{properties} \mathrm{at}$ \\ elevated temperature were investigated, where the elastic constants show high thermal stability over the \\ range of $25-500 \mathrm{C}$, with minimal variation of $6 \%$.

\section{Publication Details} \\ Shen, C., Zhang, S., Cao, W., Cong, H., Yu, H., Wang, J. \& Zhang, H. (2015). Thermal and electromechanical \\ properties of melilite-type piezoelectric single crystals. Journal Of Applied Physics, 117 (6), \\ 064106-1-064106-7.
}

\section{Authors}

Chuanying Shen, Shujun Zhang, Wenwu Cao, Hengjiang Cong, Haohai Yu, Jiyang Wang, and Huaijin Zhang 


\title{
Thermal and electromechanical properties of melilite-type piezoelectric single crystals
}

\author{
Chuanying Shen, ${ }^{1,2}$ Shujun Zhang, ${ }^{2, a)}$ Wenwu Cao, ${ }^{2}$ Hengjiang Cong, ${ }^{1}$ Haohai Yu, ${ }^{1}$ \\ Jiyang Wang, ${ }^{1}$ and Huaijin Zhang ${ }^{1, b)}$ \\ ${ }^{1}$ State Key Laboratory of Crystal Materials, Institute of Crystal Materials, Shandong University, Jinan, \\ Shandong 250100, China \\ ${ }^{2}$ Materials Research Institute, Pennsylvania State University, University Park, Pennsylvania 16802, USA
}

(Received 2 December 2014; accepted 2 February 2015; published online 11 February 2015)

\begin{abstract}
Melilite-type crystals, including $\mathrm{Ca}_{2} \mathrm{Ga}_{2} \mathrm{SiO}_{7}, \mathrm{Ca}_{2} \mathrm{MgSi}_{2} \mathrm{O}_{7}$, and $\mathrm{CaNdGa}_{3} \mathrm{O}_{7}$, were successfully grown by the Czochralski technique. Thermal properties were investigated and full matrices of electromechanical constants of these melilite crystals were evaluated by impedance method, with $d_{14}$ being on the order of 5.3-9.3 pC/N. The relationship between microstructure and electromechanical properties of the three kinds of crystals was established, in order to explore the piezoelectric origin and further optimize the piezoelectric properties. The distortion of eight-fold antiprisms and the distortion/rotation of tetrahedrons were thought to contribute to the piezoelectric $d_{14}$ and $d_{36}$, respectively. In addition, the layered structure leads to strong anisotropic behavior, accounts for the high resistivity along $\mathrm{Z}$ direction in $\mathrm{Ca}_{2} \mathrm{MgSi}_{2} \mathrm{O}_{7}$, while the disordered structure accounts for the degraded resistivity in $\mathrm{CaNdGa}_{3} \mathrm{O}_{7}$. The properties at elevated temperature were investigated, where the elastic constants show high thermal stability over the range of $25-500^{\circ} \mathrm{C}$, with minimal variation of 6\%. C 2015 AIP Publishing LLC. [http://dx.doi.org/10.1063/1.4908113]
\end{abstract}

\section{INTRODUCTION}

Mineral melilites have been found in meteorites, blast furnace slags, igneous, and metamorphic rocks. ${ }^{1}$ Melilites were also found in industrial slag and clinkers and are important component in technological glasses. ${ }^{2}$ Melilite-family compounds exhibit a general formula $\left(\mathrm{A}_{1} \mathrm{~A}_{2}\right)_{2}\left\{\left(\mathrm{~B}_{1} \mathrm{~B}_{2}\right)\right.$ $\left.\left(\mathrm{C}_{1} \mathrm{C}_{2}\right)\right\}_{3} \mathrm{O}_{7}$, where $\mathrm{A}, \mathrm{B}$, and $\mathrm{C}$ denote three distinct cationic sites, and the largest $\mathrm{A}$ site is a distorted eight-fold coordinated antiprism being occupied by divalent cation $\mathrm{A}_{1}(\mathrm{Ca}$, $\mathrm{Sr}, \mathrm{Ba}$, etc.) and/or trivalent $\mathrm{A}_{2}$ ( $\mathrm{La}, \mathrm{Nd}$, Pr, etc.); the smaller site $B$ is regular tetrahedral, which is occupied by divalent $\mathrm{B}_{1}(\mathrm{Mg}, \mathrm{Zn})$ and/or trivalent $\mathrm{B}_{2}$ cation $(\mathrm{Al}, \mathrm{Ga})$; the smallest site $\mathrm{C}$ is a distorted tetrahedral, where trivalent $\mathrm{C}_{1}$ cation $(\mathrm{Al}, \mathrm{Ga})$ and/or tetravalent $\mathrm{C}_{2}$ cation $(\mathrm{Si}, \mathrm{Ge})$ occupy this position. ${ }^{3,4}$ Melilite belongs to a tetragonal system with space group of $\overline{4} 2_{1} m,{ }^{5,6}$ the structure was firstly determined by Warren, ${ }^{7}$ and subsequently refined by Smith $^{8}$ and Bindi et al. . $^{9}$

Melilite crystals with a wide range of chemical compositions can be easily grown by Czochralski method, attracted attentions from scientists and engineers in the last decades. Much effort has been dedicated to the crystal growth and piezoelectric investigations. ${ }^{10-14}$ It was reported that the piezoelectric coefficient $d_{14}$ varied a lot for different melilite crystals $\left(\mathrm{Ca}_{2} \mathrm{MgSi}_{2} \mathrm{O}_{7}(\mathrm{CMS}), d_{14}=3.2 \mathrm{pC} / \mathrm{N} ;{ }^{10} \mathrm{Ca}_{2} \mathrm{Al}_{2} \mathrm{SiO}_{7}\right.$, $d_{14}=6.0 \mathrm{pC} / \mathrm{N} ;{ }^{11,12}$ and $\mathrm{SrGdGa}_{3} \mathrm{O}_{7}, d_{14}=14.5 \mathrm{pC} / \mathrm{N}$ (Refs. 13 and 14)). Thus, it is interesting to explore the origin of piezoelectric properties based on the microstructure. In this work, $\mathrm{Ca}_{2} \mathrm{Ga}_{2} \mathrm{SiO}_{7}$ (CGS), $\mathrm{Ca}_{2} \mathrm{MgSi}_{2} \mathrm{O}_{7}$, and $\mathrm{CaNdGa}_{3} \mathrm{O}_{7}$ (CNG) were grown by the Czochralski technique. The

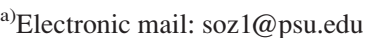

b)Electronic mail: huaijinzhang@sdu.edu.cn
}

complete set of dielectric, elastic, piezoelectric constants, and electromechanical coupling factors were determined. The relationship between microstructure and electromechanical properties of these melilite crystals were compared and discussed in relation to the tetrahedral layers and eight-fold antiprisms structure, the piezoelectric origin was studied, which will benefit the optimization of the piezoelectric properties in melilite crystals. Furthermore, the temperature dependent of electromechanical properties was investigated.

\section{EXPERIMENTAL DETAILS}

\section{A. Crystal growth and structure analysis}

The raw materials for CGS, CMS, and $\mathrm{CNG}$, including high-purity reagents $\mathrm{CaCO}_{3}, \mathrm{SiO}_{2}, \mathrm{Ga}_{2} \mathrm{O}_{3}, \mathrm{Nd}_{2} \mathrm{O}_{3}$, and $\mathrm{MgO}$, were weighed according to stoichiometric amounts to synthesize the polycrystalline compounds. Excess of $\mathrm{Ga}_{2} \mathrm{O}_{3}(1 \%$ of the total mass) was added to compensate for the evaporation during the growth process. Crystals were grown by the RF-heating Czochralski technique in an atmosphere of nitrogen (to suppress volatilization of $\mathrm{Ga}_{2} \mathrm{O}_{3}$ during the growth process) containing 2 vol. \% oxygen using iridium crucible. An [001]-oriented $\mathrm{Ca}_{2} \mathrm{Ga}_{2} \mathrm{SiO}_{7}$ crystal seed was lowered to a position slightly above the melt surface and wait until reaching thermal equilibrium, then slowly introduced into the melt. To prevent dislocations in the seed and get high quality single crystals, the necking process is important. The crystal was pulled at a speed of $0.5-1.0 \mathrm{~mm} / \mathrm{h}$ with a rotation rate of 10-30 rpm. After the growth process, the grown crystal was cooled down to room temperature at a rate of $10-30{ }^{\circ} \mathrm{C} / \mathrm{h}$ to avoid cracking caused by the anisotropic thermal stress. The growth processes of CMS and CNG crystals are similar to that of CGS crystal. 
The structure, atomic coordinate locations, and bond lengths of the as-grown crystals were determined and refined by X-ray powder diffraction (XRD) using Jade10 software.

\section{B. Thermal properties}

The specific heat was measured using a simultaneous thermal analyzer (Perkin Elmer Diamond: DSC). Crystal samples with dimensions of $5 \times 6 \times 7 \mathrm{~mm}^{3}$ were used to determine the thermal expansion coefficients using a thermal mechanical analyzer (PerkinElmer model: Diamond TMA).

\section{Electromechanical properties}

Melilite crystals with $\overline{4} 2 m$ space group possess ten nonzero independent electromechanical constants, including two dielectric permittivities $\varepsilon_{11}$ and $\varepsilon_{33}$; six elastic compliances $s_{11}, s_{12}, s_{13}, s_{33}, s_{44}$, and $s_{66}$; and two piezoelectric coefficients $d_{14}$ and $d_{36}$. Different geometry specimens were made based on the IEEE Standards on Piezoelectricity ${ }^{15}$ for electromechanical constants determination, as shown in Figure 1. The dimensions of the specimens were $8 \times 8$ $\times 2 \mathrm{~mm}^{3}$ for the $X$ - and Z-cut square plates and $12 \times 4$ $\times 2 \mathrm{~mm}^{3}$ for the long bars. All specimens were vacuumsputtered Pt thin films $(200 \mathrm{~nm})$ on the parallel large faces as electrodes.

The dielectric constants were determined from capacitances measured using a high precision LCR meter (Agilent HP $4184 \mathrm{~A})$ at $100 \mathrm{~Hz}-100 \mathrm{kHz}$. The resonance and antiresonance frequencies used to calculate the elastic constants and electromechanical coupling factors were measured using an Agilent HP 4194A impedance/gain-phase analyzer. The electrical resistivities (above $300^{\circ} \mathrm{C}$ ) were determined by measuring the currents of $\mathrm{X}$ - and Z-plates under an applied voltage of $\pm 100 \mathrm{~V}$, using a source meter (Keithley 2410C, MetricTest, Hayward, CA).

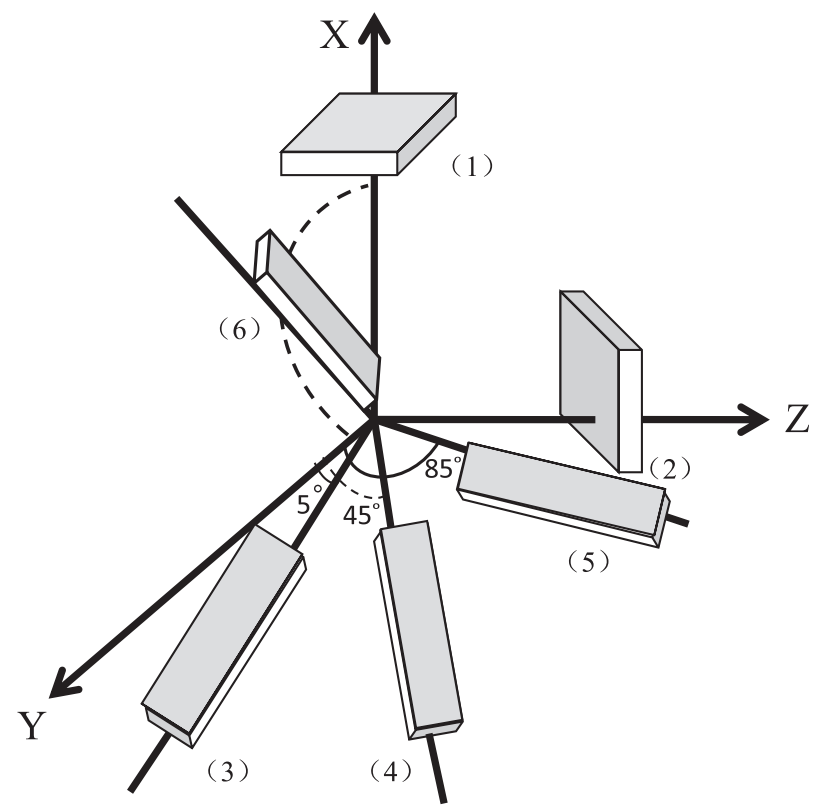

FIG. 1. Schematic of specimens: (1) $X$-cut; (2) Z-cut; (3) $x y t 5^{\circ}$; (4) $x y t 45^{\circ}$; (5) $x y 85^{\circ}$; and (6) $z x t 45^{\circ}$.

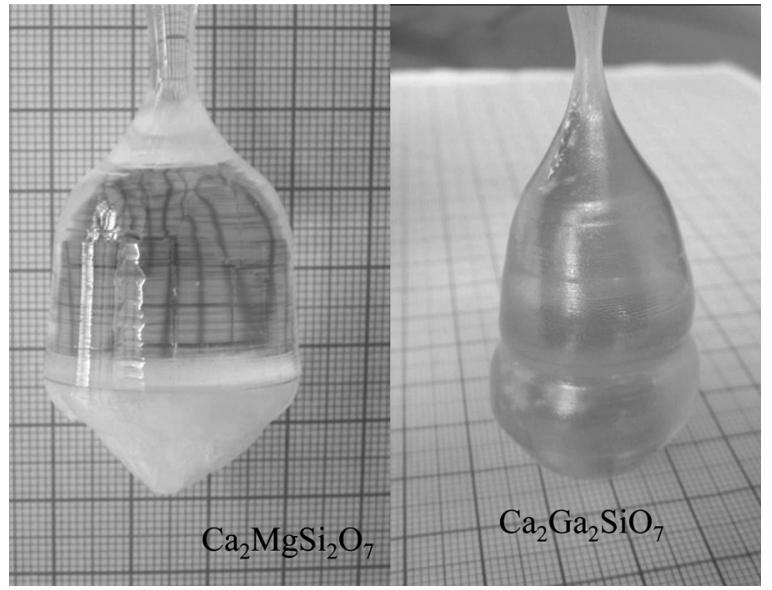

FIG. 2. The as-grown $\mathrm{Ca}_{2} \mathrm{Ga}_{2} \mathrm{SiO}_{7}$ and $\mathrm{Ca}_{2} \mathrm{MgSi}_{2} \mathrm{O}_{7}$ crystals pulled along [001]-direction.

\section{RESULTS AND DISCUSSION}

\section{A. Crystal growth and structural analysis}

Figure 2 shows the as-grown $\mathrm{Ca}_{2} \mathrm{Ga}_{2} \mathrm{SiO}_{7}$ and $\mathrm{Ca}_{2} \mathrm{MgSi}_{2} \mathrm{O}_{7}$ crystals pulled along [001]-direction. X-ray powder diffraction showing the as-grown crystals consists of a single phase belonging to the $P \overline{4} 2_{1} m$ space group. The structure of $\mathrm{Ca}_{2} \mathrm{Ga}_{2} \mathrm{SiO}_{7}$ was given in Figure 3, from which, regular $\mathrm{GaO}_{4}$ tetrahedrons and corner-sharing irregular tetrahedrons $\left(\mathrm{GaO}_{4} / \mathrm{SiO}_{4}\right)$ forming the tetrahedral layers $\left(\mathrm{GaO}_{4}\right.$ and $\mathrm{SiO}_{4}$ tetrahedrons linked each other forming fivemembered rings) in the $X Y$ plane, while the layers are linked

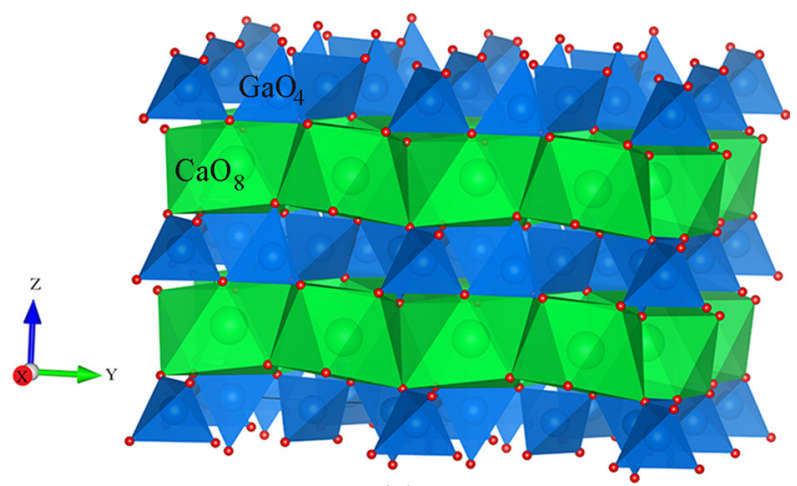

(a)

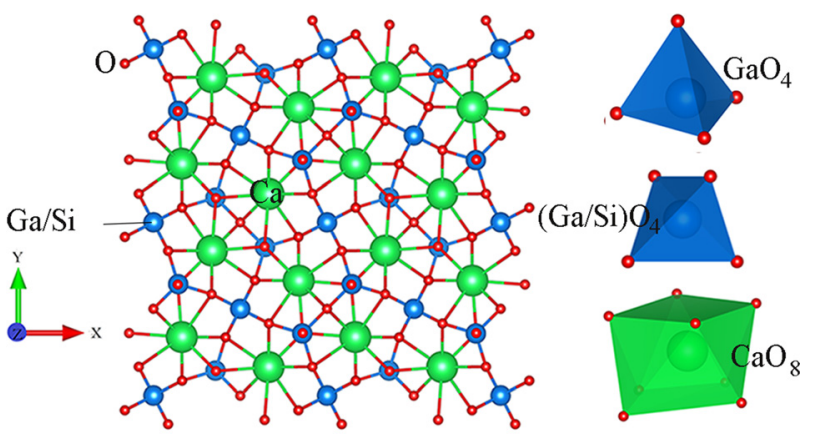

(b)

(c)

FIG. 3. Projection of the average crystal structure of $\mathrm{Ca}_{2} \mathrm{Ga}_{2} \mathrm{SiO}_{7}$ (a) projected along $X$-direction, (b) projected along $Z$-direction, and (c) $\mathrm{GaO}_{4} / \mathrm{SiO}_{4}$ tetrahedrons and $\mathrm{CaO}_{8}$ antiprism. 
together along the $\mathrm{Z}$-axis by $\mathrm{Ca}$ cations on eight-fold coordinate sites. The structure of $\mathrm{Ca}_{2} \mathrm{MgSi}_{2} \mathrm{O}_{7}$ crystal is similar to that of $\mathrm{Ca}_{2} \mathrm{Ga}_{2} \mathrm{SiO}_{7}$, where the $\mathrm{Mg}^{2+}$ ions are located at regular tetrahedral positions, while $\mathrm{Si}^{4+}$ ions are located at irregular tetrahedral positions. Similarly, $\mathrm{CaNdGa}_{3} \mathrm{O}_{7}$ crystals were found to possess the same structure, where $\mathrm{Ca}^{2+}$ and $\mathrm{Nd}^{3+}$ ions (distributed randomly with a ratio of $1: 1$ ) are located at the eight-fold coordinate antiprisms, while $\mathrm{Ga}^{3+}$ cations are located at tetrahedral positions.

\section{B. Thermal properties}

The temperature dependence of specific heat $\left(C_{p}\right)$ for $\mathrm{Ca}_{2} \mathrm{Ga}_{2} \mathrm{SiO}_{7}$ and $\mathrm{Ca}_{2} \mathrm{MgSi}_{2} \mathrm{O}_{7}$ crystals is shown in Figure 4. One can see that the specific heat of $\mathrm{Ca}_{2} \mathrm{Ga}_{2} \mathrm{SiO}_{7}$ increases linearly from $0.629 \mathrm{~J} \cdot \mathrm{g}^{-1} \cdot{ }^{\circ} \mathrm{C}^{-1}$ to $0.985 \mathrm{~J} \cdot \mathrm{g}^{-1} \cdot{ }^{\circ} \mathrm{C}^{-1}$ over the temperature range of $20-300^{\circ} \mathrm{C}$. A small peak was observed at $87^{\circ} \mathrm{C}$ for $\mathrm{Ca}_{2} \mathrm{MgSi}_{2} \mathrm{O}_{7}$ crystals, which is associated with the incommensurate-normal phase transition, ${ }^{16}$ above which, the specific heat was found to increase linearly from $0.889 \mathrm{~J} \cdot \mathrm{g}^{-1} \cdot{ }^{\circ} \mathrm{C}^{-1}$ to $1.120 \mathrm{~J} \cdot \mathrm{g}^{-1} \cdot{ }^{\circ} \mathrm{C}^{-1}$. The specific heat of $\mathrm{CNG}$ is smaller than those of CMS and CGS, increasing linearly from $0.456 \mathrm{~J} \cdot \mathrm{g}^{-1} \cdot{ }^{\circ} \mathrm{C}^{-1}$ to $0.598 \mathrm{~J} / \mathrm{g} \cdot{ }^{\circ} \mathrm{C}$ over the same temperature range.

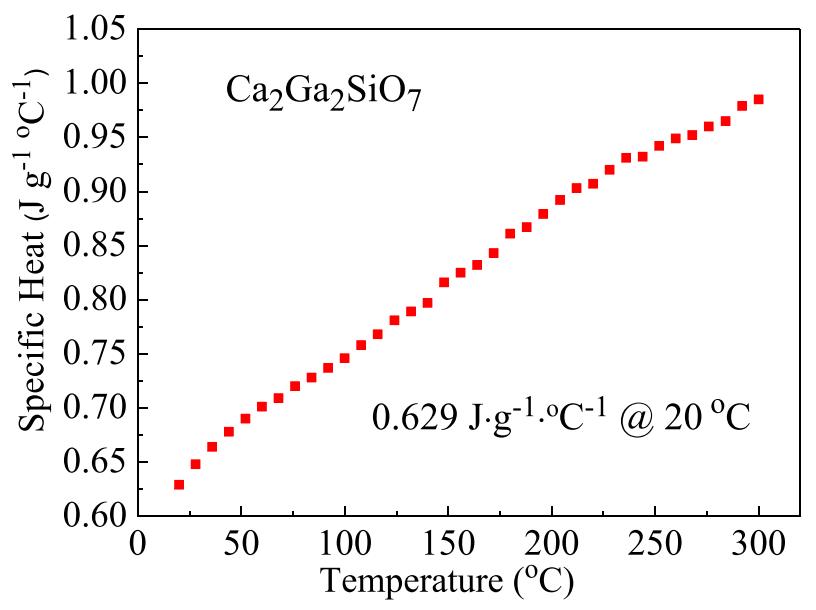

(a)

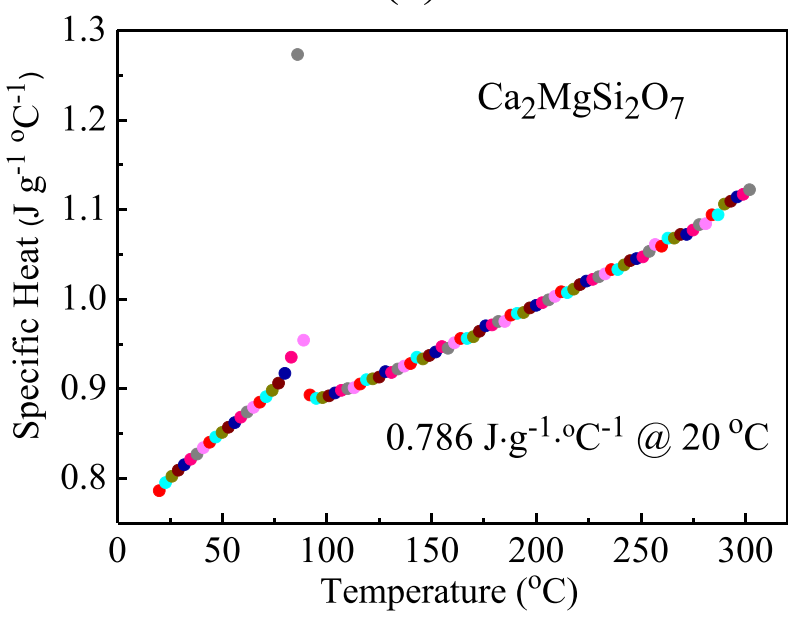

(b)

FIG. 4. The specific heat of (a) $\mathrm{Ca}_{2} \mathrm{Ga}_{2} \mathrm{SiO}_{7}$ and (b) $\mathrm{Ca}_{2} \mathrm{MgSi}_{2} \mathrm{O}_{7}$ crystals as a function of temperature.
Figure 5 presents the temperature dependence of thermal expansions for (a) CGS and (b) CMS crystals. From Figure 5(a), the thermal expansions were found to increase slightly with temperature for CGS over the temperature range of $25-500^{\circ} \mathrm{C}$ with average thermal expansion coefficients of $5.7 \times 10^{-6} /{ }^{\circ} \mathrm{C}$ and $8.7 \times 10^{-6} /{ }^{\circ} \mathrm{C}$ along the $X$ - and Z-directions, respectively. For CMS, the thermal expansion along $X$-direction was found to increase linearly over the studied temperature range, while for $Z$-direction, it decreases in the range of $25-87^{\circ} \mathrm{C}$, then increases slightly up to $500^{\circ} \mathrm{C}$, with the inversion point being associated with the incommensurate-normal transition temperature. ${ }^{17}$ Above $87^{\circ} \mathrm{C}$, the average thermal expansion coefficients were calculated to be $8.0 \times 10^{-6} /{ }^{\circ} \mathrm{C}$ and $8.8 \times 10^{-6} /{ }^{\circ} \mathrm{C}$ along $X$ - and $Z$-directions, showing minimal variation; whereas for $\mathrm{CNG}$, they are $5.4 \times 10^{-6} /{ }^{\circ} \mathrm{C}$ and $6.6 \times 10^{-6} /{ }^{\circ} \mathrm{C}$, respectively.

Using the Archimedes method, the densities of CGS and CMS at room temperature were measured to be $3.795 \mathrm{~g} / \mathrm{cm}^{3}$ and $2.960 \mathrm{~g} / \mathrm{cm}^{3}$, respectively. The density at different temperatures can be evaluated based on the thermal expansion curves, as shown in the inset of Figure 5. Over the temperature range of $25-500{ }^{\circ} \mathrm{C}$, the densities of CGS, CMS, and CNG were found to decrease linearly from $3.795 \mathrm{~g} / \mathrm{cm}^{3}$ to $3.790 \mathrm{~g} / \mathrm{cm}^{3}$, from $2.960 \mathrm{~g} / \mathrm{cm}^{3}$ to $2.946 \mathrm{~g} / \mathrm{cm}^{3}$, and from $5.139 \mathrm{~g} / \mathrm{cm}^{3}$ to $5.097 \mathrm{~g} / \mathrm{cm}^{3}$, respectively.

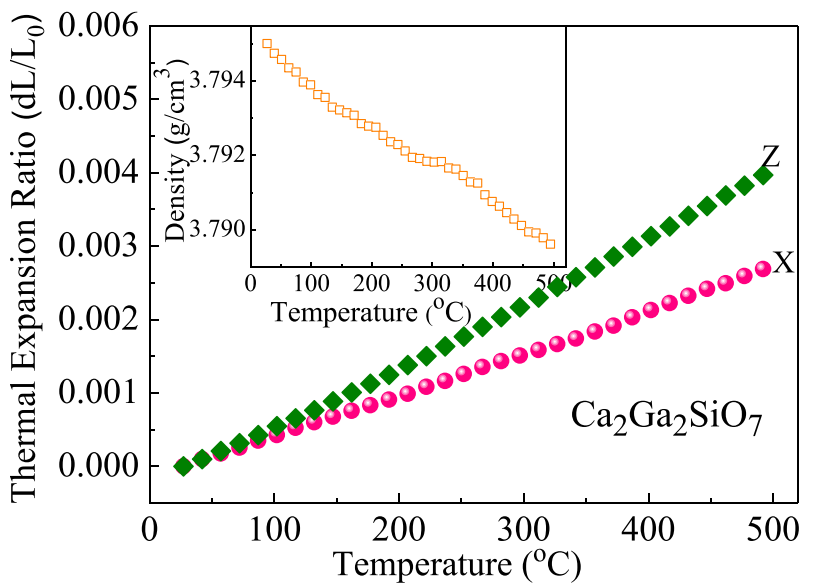

(a)

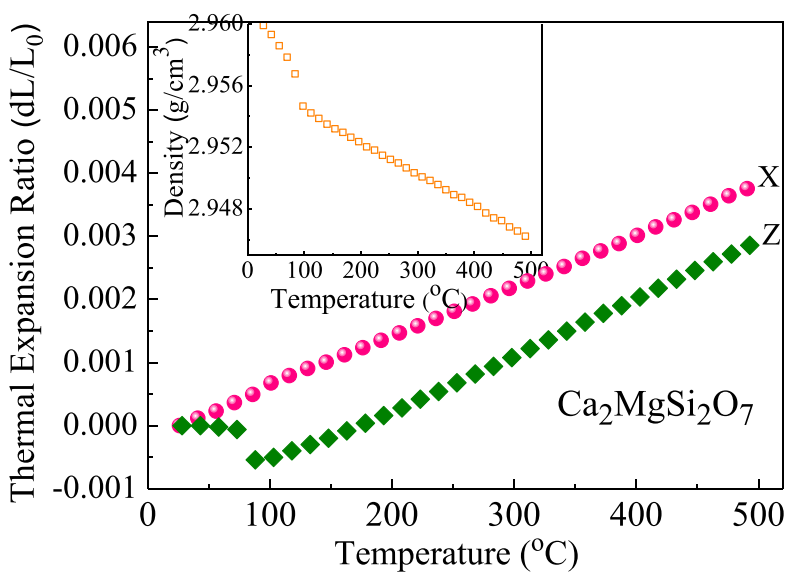

(b)

FIG. 5. The thermal expansions of (a) $\mathrm{Ca}_{2} \mathrm{Ga}_{2} \mathrm{SiO}_{7}$ and (b) $\mathrm{Ca}_{2} \mathrm{MgSi}_{2} \mathrm{O}_{7}$ as a function of temperature. 
TABLE I. The room temperature electromechanical constants of melilite crystals.

\begin{tabular}{|c|c|c|c|c|c|c|}
\hline \multirow[b]{2}{*}{ Crystals } & \multicolumn{6}{|c|}{ Dielectric constants $\varepsilon_{i i}^{T} / \varepsilon_{0}$} \\
\hline & \multicolumn{2}{|l|}{$\varepsilon_{11}^{T} / \varepsilon_{0}$} & \multicolumn{4}{|c|}{$\varepsilon_{33}^{T} / \varepsilon_{0}$} \\
\hline $\mathrm{CaNdGa}_{3} \mathrm{O}_{7}$ (Ref. 18) & \multicolumn{2}{|l|}{16.8} & \multicolumn{2}{|c|}{10.9} & & \\
\hline $\mathrm{Ca}_{2} \mathrm{Ga}_{2} \mathrm{SiO}_{7}$ & \multicolumn{2}{|l|}{12.6} & \multicolumn{2}{|r|}{7.4} & & \\
\hline \multirow[t]{3}{*}{$\mathrm{Ca}_{2} \mathrm{MgSi}_{2} \mathrm{O}_{7}$} & 11.7 & & & 8.0 & & \\
\hline & \multicolumn{6}{|c|}{ Elastic compliance constants $s_{i j}\left(\mathrm{pm}^{2} / \mathrm{N}\right)$} \\
\hline & $s_{11}^{E}$ & $s_{12}^{E}$ & $s_{13}^{E}$ & $s_{33}^{E}$ & $s_{44}^{E}$ & $s_{66}^{E}$ \\
\hline $\mathrm{CaNdGa}_{3} \mathrm{O}_{7}$ (Ref. 18) & 8.5 & -3.5 & -1.9 & 6.8 & 26.0 & 16.5 \\
\hline $\mathrm{Ca}_{2} \mathrm{Ga}_{2} \mathrm{SiO}_{7}$ & 8.2 & -3.3 & -1.9 & 8.1 & 31.1 & 15.0 \\
\hline \multirow[t]{3}{*}{$\mathrm{Ca}_{2} \mathrm{MgSi}_{2} \mathrm{O}_{7}$} & 9.0 & -4.4 & -2.0 & 8.4 & 33.6 & 18.6 \\
\hline & \multicolumn{6}{|c|}{ Elastic stiffness constants $c_{i j}\left(10^{10} \mathrm{~N} / \mathrm{m}^{2}\right)$} \\
\hline & $c_{11}^{E}$ & $c_{12}^{E}$ & $c_{13}^{E}$ & $c_{33}^{E}$ & $c_{44}^{E}$ & $c_{66}^{E}$ \\
\hline $\mathrm{CaNdGa}_{3} \mathrm{O}_{7}$ (Ref. 18) & 16.9 & 8.5 & 7.1 & 18.7 & 3.8 & 6.1 \\
\hline $\mathrm{Ca}_{2} \mathrm{Ga}_{2} \mathrm{SiO}_{7}$ & 16.8 & 8.1 & 5.9 & 15.1 & 3.2 & 6.7 \\
\hline \multirow[t]{3}{*}{$\mathrm{Ca}_{2} \mathrm{MgSi}_{2} \mathrm{O}_{7}$} & 17.5 & 10.0 & 6.6 & 15.1 & 3.0 & 5.4 \\
\hline & \multicolumn{6}{|c|}{ Piezoelectric coefficients $d_{i j}(\mathrm{pC} / \mathrm{N})$ and $e_{i j}\left(\mathrm{C} / \mathrm{m}^{2}\right)$} \\
\hline & $d_{14}$ & $d_{36}$ & $e_{14}$ & & $e_{36}$ & \\
\hline $\mathrm{CaNdGa}_{3} \mathrm{O}_{7}$ (Ref. 18) & 9.3 & 1.7 & 0.36 & & 0.10 & \\
\hline $\mathrm{Ca}_{2} \mathrm{Ga}_{2} \mathrm{SiO}_{7}$ & 6.4 & 1.4 & 0.21 & & 0.09 & \\
\hline \multirow[t]{3}{*}{$\mathrm{Ca}_{2} \mathrm{MgSi}_{2} \mathrm{O}_{7}$} & 5.3 & 4.3 & 0.16 & & 0.23 & \\
\hline & \multicolumn{6}{|c|}{ Electromechanical coupling factors $k_{i j}(\%)$} \\
\hline & $k_{14}$ & & $k_{36}$ & & & \\
\hline $\mathrm{CaNdGa}_{3} \mathrm{O}_{7}$ (Ref. 18) & 14.9 & & 4.2 & & & \\
\hline $\mathrm{Ca}_{2} \mathrm{Ga}_{2} \mathrm{SiO}_{7}$ & 10.9 & & 4.5 & & & \\
\hline $\mathrm{Ca}_{2} \mathrm{MgSi}_{2} \mathrm{O}_{7}$ & 8.0 & & 8.3 & & & \\
\hline
\end{tabular}

\section{Room temperature electromechanical properties}

Table I lists the full matrices electromechanical constants of $\mathrm{Ca}_{2} \mathrm{Ga}_{2} \mathrm{SiO}_{7}$ and $\mathrm{Ca}_{2} \mathrm{MgSi}_{2} \mathrm{O}_{7}$, and compared with $\mathrm{CaNdGa}_{3} \mathrm{O}_{7}$ (Ref. 18) crystals, from which the dielectric constant $\varepsilon_{11}^{T} / \varepsilon_{0}$ and piezoelectric coefficient $d_{14}$ were found to be $11.7-16.8$ and $5.3-9.3 \mathrm{pC} / \mathrm{N}$, respectively.

The piezoelectric coefficient $d_{14}$ of melilite crystals was thought to be attributed to the distortion (in YZ-plane) of the relatively soft eight-fold antiprisms, while $d_{36}$ mainly comes from the distortion/rotation (in $X Y$-plane) of the rigid tetrahedral layers. ${ }^{18}$ In order to verify this hypothesis and further explore the piezoelectric origin, some structural parameters, including ionic radius, bond length, the ratio of bond length to ionic radius in eight-fold antiprisms, and piezoelectric coefficients are summarized in Table II.

For $\mathrm{Ca}_{2} \mathrm{Ga}_{2} \mathrm{SiO}_{7}$ and $\mathrm{Ca}_{2} \mathrm{MgSi}_{2} \mathrm{O}_{7}$, they have same $\mathrm{CaO}_{8}$ antiprisms and similar $d_{14}$ values, but different tetrahedrons and coefficients of $d_{36}$, hence, $d_{36}$ mainly comes from the distortion/rotation of the tetrahedral layers. For $\mathrm{CaNdGa}_{3} \mathrm{O}_{7}$ and $\mathrm{Ca}_{2} \mathrm{Ga}_{2} \mathrm{SiO}_{7}$ crystals, they have similar $d_{36}$ values and same $\mathrm{GaO}_{4}$ regular tetrahedrons but different irregular tetrahedrons, so $d_{36}$ most probably attributes to the distortion/rotation of the regular tetrahedrons. From the aspect of microstructure, the corner linking of the irregular tetrahedrons restricts the rotation patterns, ${ }^{19}$ so the distortion/ rotation of regular tetrahedrons is easier than that of irregular ones under an applied electric field along the Z-direction, which also confirms that the piezoelectric $d_{36}$ is originated from the distortion/rotation of the regular tetrahedrons.

As discussed previously, $\mathrm{Ca}_{2} \mathrm{Ga}_{2} \mathrm{SiO}_{7}$ and $\mathrm{Ca}_{2} \mathrm{MgSi}_{2} \mathrm{O}_{7}$ have same $\mathrm{CaO}_{8}$ antiprisms and similar $d_{14}$ values, while $\mathrm{CaNdGa}_{3} \mathrm{O}_{7}$ crystals possess different antiprisms and larger piezoelectric $d_{14}$, so $d_{14}$ most probably attributes to the distortion of eight-fold antiprisms. In eight-fold antiprisms of the three melilite crystals, a larger bond length and/or a larger ratio of bond length to ionic radius indicates a larger space between the cation and oxygen ion, leading to "soft" antiprism (larger deformation) under applied electric field, accounting for the larger value of $d_{14}$.

\section{Temperature dependent electrical resistivity}

Figure 6 illustrates the dc electrical resistivity versus temperature for $\mathrm{CaNdGa}_{3} \mathrm{O}_{7}, \mathrm{Ca}_{2} \mathrm{Ga}_{2} \mathrm{SiO}_{7}$, and $\mathrm{Ca}_{2} \mathrm{MgSi}_{2} \mathrm{O}_{7}$, exhibiting the expected linear Arrhenius behavior. According to the Arrhenius equation, the activation energies $\left(E_{a}\right)$ along $X$ - and $Z$-directions can be calculated from the slope of the curves and were found to be in the range of $0.78-1.31 \mathrm{eV}$, related to the conductivity of the oxygen vacancies. It is interesting to note that the magnitude of the resistivity follows the trend of $\mathrm{Ca}_{2} \mathrm{MgSi}_{2} \mathrm{O}_{7}>\mathrm{Ca}_{2} \mathrm{Ga}_{2} \mathrm{SiO}_{7}$ $>\mathrm{CaNdGa}_{3} \mathrm{O}_{7}$, which can be explained by the following two factors:

(1) The layered crystal structure: The tetrahedral layers interconnected by the large A site cations are vertical to the Z-direction, acting as barriers against charge

TABLE II. The structure and piezoelectric properties of melilite-type $\mathrm{CaNdGa}_{3} \mathrm{O}_{7}, \mathrm{Ca}_{2} \mathrm{Ga}_{2} \mathrm{SiO}_{7}$, and $\mathrm{Ca}_{2} \mathrm{MgSi}_{2} \mathrm{O}_{7}$ crystals.

\begin{tabular}{|c|c|c|c|c|c|}
\hline & & & $\mathrm{CaNdGa}_{3} \mathrm{O}_{7}$ & $\mathrm{Ca}_{2} \mathrm{Ga}_{2} \mathrm{SiO}_{7}$ & $\mathrm{Ca}_{2} \mathrm{MgSi}_{2} \mathrm{O}_{7}$ \\
\hline \multirow[t]{6}{*}{ In layers } & \multirow[t]{3}{*}{ Regular tetrahedron } & Category & $\mathrm{GaO}_{4}$ & $\mathrm{GaO}_{4}$ & $\mathrm{MgO}_{4}$ \\
\hline & & Ion radius $(\AA)$ & 0.47 & 0.47 & 0.57 \\
\hline & & Bond length $(\AA)$ & 1.827 & 1.821 & 1.921 \\
\hline & \multirow[t]{3}{*}{ Irregular tetrahedron } & Category & $\mathrm{GaO}_{4}$ & $\mathrm{GaO}_{4} / \mathrm{SiO}_{4}$ & $\mathrm{SiO}_{4}$ \\
\hline & & Ion radius $(\AA)$ & 0.47 & $0.47 / 0.26$ & 0.26 \\
\hline & & Bond length $(\AA)$ & 1.785 & 1.737 & 1.629 \\
\hline \multirow[t]{3}{*}{ Between layers } & \multirow[t]{3}{*}{ Eight-fold antiprism } & Category & $\mathrm{CaO}_{8} / \mathrm{NdO}_{8}$ & $\mathrm{CaO}_{8}$ & $\mathrm{CaO}_{8}$ \\
\hline & & Average bond length $(\AA)$ & 2.598 & 2.581 & 2.568 \\
\hline & & Ratio & 2.331 & 2.304 & 2.293 \\
\hline \multirow{2}{*}{\multicolumn{2}{|c|}{ Piezoelectric coefficient $(\mathrm{pC} / \mathrm{N})$}} & $d_{14}$ & 9.3 & 6.4 & 5.3 \\
\hline & & $d_{36}$ & 1.7 & 1.4 & 4.3 \\
\hline
\end{tabular}




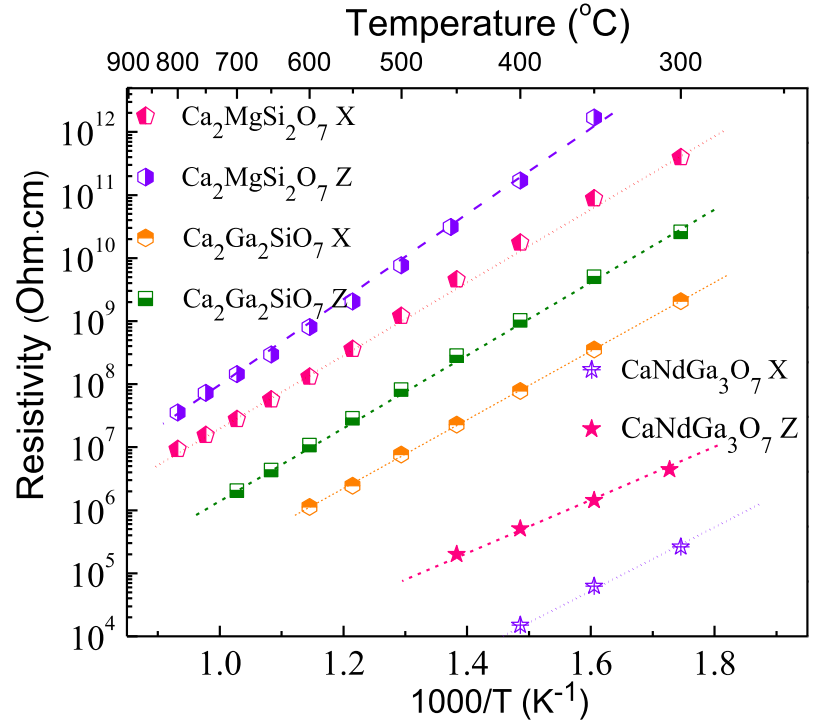

FIG. 6. Temperature dependent electrical resistivity of $\mathrm{CaNdGa}_{3} \mathrm{O}_{7}$, $\mathrm{Ca}_{2} \mathrm{Ga}_{2} \mathrm{SiO}_{7}$, and $\mathrm{Ca}_{2} \mathrm{MgSi}_{2} \mathrm{O}_{7}$ crystals.

transport. $^{20,21}$ The bond lengths of the eight-fold antiprisms follow the trend of $\mathrm{Ca}_{2} \mathrm{MgSi}_{2} \mathrm{O}_{7}<\mathrm{Ca}_{2} \mathrm{Ga}_{2} \mathrm{SiO}_{7}$ $<\mathrm{CaNdGa}_{3} \mathrm{O}_{7}$, where the shorter bond length means shorter distance between layers, resulting in a higher resistivity. This will also explain the higher resistivity along the $Z$-direction when compared to that along $X$-direction, as observed for all three crystals.

(2) The disordered structure: In the structure of $\mathrm{CaNdGa}_{3} \mathrm{O}_{7}$, $\mathrm{Ca}^{2+}$ and $\mathrm{Nd}^{3+}$ are distributed randomly with a ratio of 1:1 in eight coordinated sites, whereas in $\mathrm{Ca}_{2} \mathrm{Ga}_{2} \mathrm{SiO}_{7}$, $\mathrm{Si}^{4+}$ and half of $\mathrm{Ga}^{3+}$ are distributed randomly in the irregular tetrahedral sites. It was reported that a high disorder level would induce phonon scattering, decreasing the electrical resistivity in disordered langasite-type piezoelectric crystals. $^{22}$ Analogous to this, the lower resistivity observed in $\mathrm{CaNdGa}_{3} \mathrm{O}_{7}$ crystals maybe related to the disordered structure (due to the similar ionic radii, $\mathrm{r}^{\mathrm{Ca}}(2+)=1.12 \AA$ and $\left.\mathrm{r}^{\mathrm{Nd}}(3+)=1.11 \AA\right) .{ }^{23}$ Similarly, the structure in $\mathrm{Ca}_{2} \mathrm{Ga}_{2} \mathrm{SiO}_{7}$ gives rise to higher resistivity than that of $\mathrm{CaNdGa}_{3} \mathrm{O}_{7}$ (due to the large difference of ionic radii $\mathrm{r}^{\mathrm{Ga}}(4+)=0.47 \AA$ and $\left.\mathrm{r}^{\mathrm{Si}}(4+)=0.26 \AA\right),{ }^{23}$ but lower than that of $\mathrm{Ca}_{2} \mathrm{MgSi}_{2} \mathrm{O}_{7}$.

\section{E. Temperature dependent dielectric and piezoelectric properties}

Figure 7 presents the dielectric behaviors measured at $100 \mathrm{kHz}$ as a function of temperature for $\mathrm{CaNdGa}_{3} \mathrm{O}_{7}$, $\mathrm{Ca}_{2} \mathrm{Ga}_{2} \mathrm{SiO}_{7}$, and $\mathrm{Ca}_{2} \mathrm{MgSi}_{2} \mathrm{O}_{7}$ crystals. As observed in the inset of Figure $7(\mathrm{a})$, the relative permittivity $\varepsilon_{11}^{T} / \varepsilon_{0}$ of $\mathrm{CaNdGa}_{3} \mathrm{O}_{7}$ was found to increase markedly over the temperature range of $25-300^{\circ} \mathrm{C}$, whereas the relative permittivities of the other two crystals increase slightly over the range of $25-500^{\circ} \mathrm{C}$. From Figure 7 (a), all temperature coefficients of permittivity ( $\mathrm{TC} \varepsilon$ ) were found to be positive, which can be explained based on the value of dielectric permittivity and dielectric loss using the modified Clausius-Mosotti equation $^{24,25}$

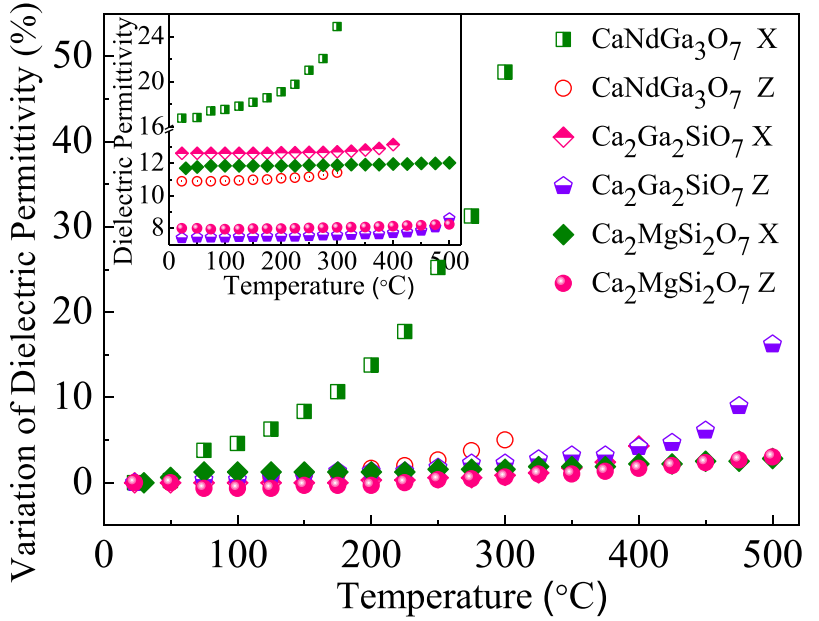

(a)

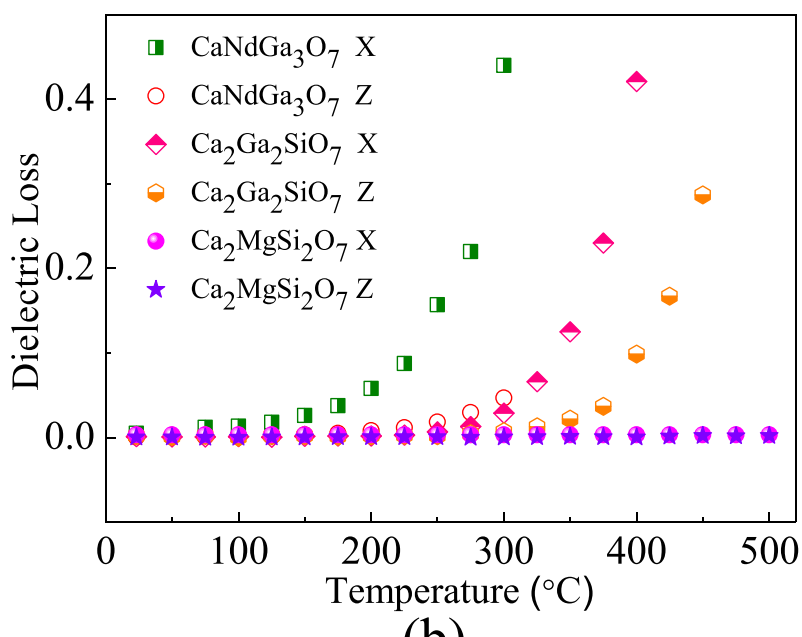

(b)

FIG. 7. The dielectric behaviors as a function of temperature for $\mathrm{CaNdGa}_{3} \mathrm{O}_{7}, \mathrm{Ca}_{2} \mathrm{Ga}_{2} \mathrm{SiO}_{7}$, and $\mathrm{Ca}_{2} \mathrm{MgSi}_{2} \mathrm{O}_{7}$ crystals along $X$ - and $Z$-axes.

$$
\mathrm{TC} \varepsilon=\frac{(\varepsilon-1)(\varepsilon+2)}{\varepsilon}(A+B+C)+0.05 \tan \delta,
$$

where $(A+B)$ indicates the effect of volume expansion with increasing temperature; $C$ corresponds to the temperature dependence of the polarizability of the intrinsic ions and electrons with constant volume. ${ }^{24,25}$ For materials with relative permittivities of $2.5<\varepsilon_{i i} / \varepsilon_{0}<10$, ionic and electronic polarizability are comparable, and the $\mathrm{TC} \varepsilon$ possesses a negative value if electronic polarizability dominating, and a positive value if ionic polarizability dominating, so the positive $\mathrm{TC} \varepsilon$ of $\mathrm{Ca}_{2} \mathrm{Ga}_{2} \mathrm{SiO}_{7}$ and $\mathrm{Ca}_{2} \mathrm{MgSi}_{2} \mathrm{O}_{7}$ crystals with $2.5<\varepsilon_{33} / \varepsilon_{0}<10$ was dominated by the ionic polarizability. For materials with relative permittivities $\varepsilon_{33} / \varepsilon_{0} \geq 10$, TC $\varepsilon$ can be evaluated from the simplified equation

$$
\mathrm{TC} \varepsilon=\text { Constant }-\alpha \varepsilon,
$$

where $\alpha$ is the linear thermal expansion coefficient. TC $\varepsilon$ decreased with increasing dielectric permittivity and shifts negatively when permittivity increased to beyond a certain value. ${ }^{24,25}$ For materials with relative permittivities $\varepsilon_{33} / \varepsilon_{0} \geq 10$ and high dielectric loss $\tan \delta>0.1 \%$, the TC $\varepsilon$ was dominated 
by dielectric loss and can be calculated by the following formula: ${ }^{24,25}$

$$
\mathrm{TC} \varepsilon=0.05 \tan \delta-\alpha \varepsilon \text {. }
$$

As can be seen from Figure 7(b), the dielectric loss was observed to increase significantly at $250{ }^{\circ} \mathrm{C}$ for $\mathrm{CaNdGa}_{3} \mathrm{O}_{7}$ and at $300{ }^{\circ} \mathrm{C}$ for $\mathrm{Ca}_{2} \mathrm{Ga}_{2} \mathrm{SiO}_{7}$, respectively, resulting in a remarkable increase in $\mathrm{TC} \varepsilon$ over the studied temperature range. The high dielectric loss was believed to be related to their high ionic conductivity (low resistivity) at elevated temperatures.

Figure 8 presents the elastic constants as a function of temperature for $\mathrm{Ca}_{2} \mathrm{Ga}_{2} \mathrm{SiO}_{7}$ and $\mathrm{Ca}_{2} \mathrm{MgSi}_{2} \mathrm{O}_{7}$ crystals. From which, the diagonal components increase slightly with increasing temperature up to $500^{\circ} \mathrm{C}$, while the off diagonal elastic constants showing opposite tendency, decrease slightly over the studied temperature range. Both crystals exhibit high thermal stability of elastic constant over the range of $25-500{ }^{\circ} \mathrm{C}$ with minimal variation of $6 \%$.

Piezoelectric coefficients as a function of temperature for $\mathrm{Ca}_{2} \mathrm{Ga}_{2} \mathrm{SiO}_{7}$ and $\mathrm{Ca}_{2} \mathrm{MgSi}_{2} \mathrm{O}_{7}$ crystals were determined, and compared with those of $\mathrm{CaNdGa}_{3} \mathrm{O}_{7}$, as given in Figure 9. For $\mathrm{CaNdGa}_{3} \mathrm{O}_{7}, d_{14}$ maintained similar values over the

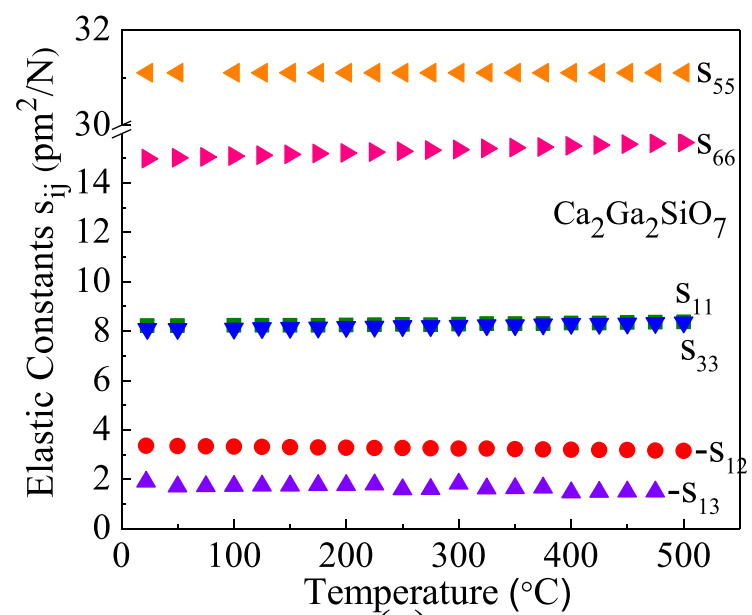

(a)

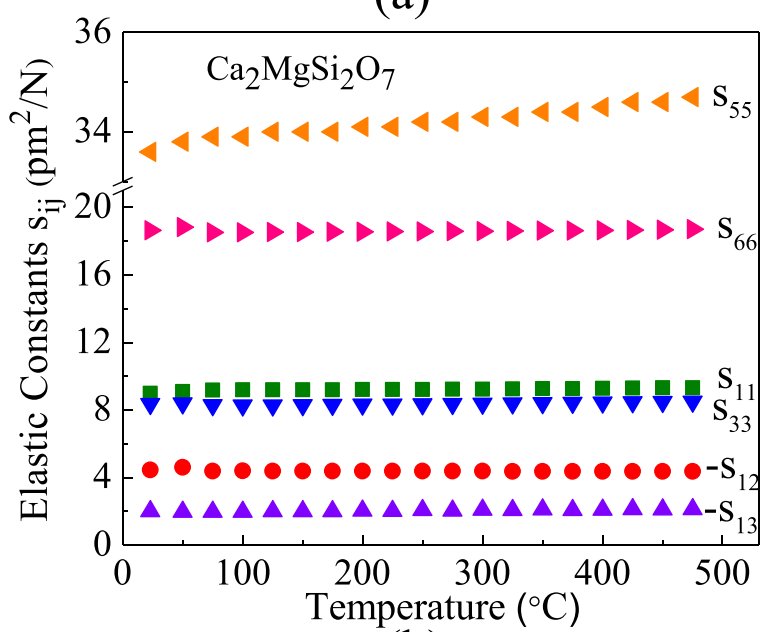

(b)

FIG. 8. The elastic constants as a function of temperature for $\mathrm{Ca}_{2} \mathrm{Ga}_{2} \mathrm{SiO}_{7}$ and $\mathrm{Ca}_{2} \mathrm{MgSi}_{2} \mathrm{O}_{7}$ crystals.

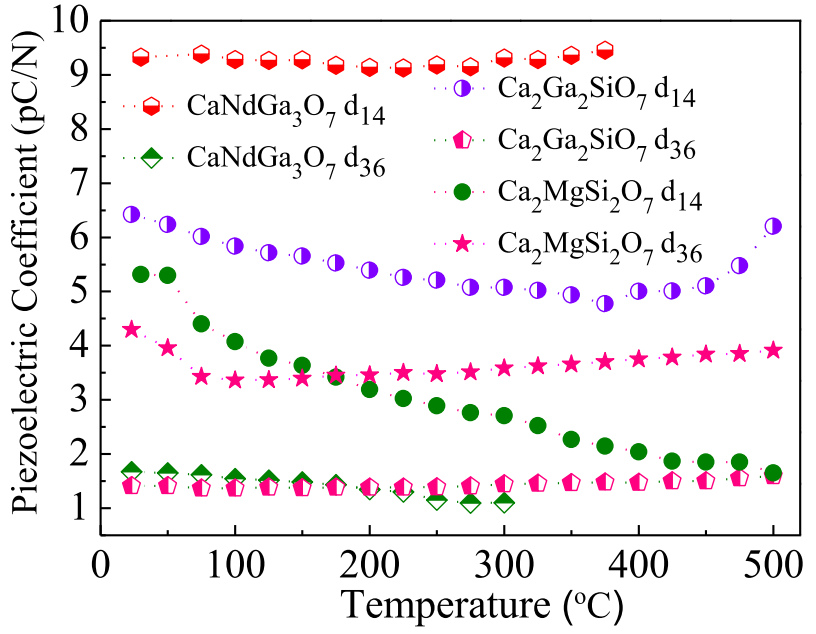

FIG. 9. Piezoelectric coefficients as a function of temperature for $\mathrm{CaNdGa}_{3} \mathrm{O}_{7}, \mathrm{Ca}_{2} \mathrm{Ga}_{2} \mathrm{SiO}_{7}$, and $\mathrm{Ca}_{2} \mathrm{MgSi}_{2} \mathrm{O}_{7}$ crystals.

temperature range of $25-400{ }^{\circ} \mathrm{C}$, while $d_{36}$ is decreased slightly from $1.7 \mathrm{pC} / \mathrm{N}$ to $1.1 \mathrm{pC} / \mathrm{N}$ over the range of $25-300{ }^{\circ} \mathrm{C}$. Above these temperature ranges, the piezoelectric properties cannot be determined by impedance method, due to their low resistivity at elevated temperatures.

For $\mathrm{Ca}_{2} \mathrm{Ga}_{2} \mathrm{SiO}_{7}$, the value of $d_{14}$ is decreased from 6.4 $\mathrm{pC} / \mathrm{N}$ to $4.8 \mathrm{pC} / \mathrm{N}$ in the range of $25-375^{\circ} \mathrm{C}$, above which, the value is increased slightly to $6.2 \mathrm{pC} / \mathrm{N}$ at $500{ }^{\circ} \mathrm{C}$. The increase in $d_{14}$ above $375^{\circ} \mathrm{C}$ is associated with the remarkable increase in dielectric permittivity $\varepsilon_{11}^{T}$. On the other hand, for $\mathrm{Ca}_{2} \mathrm{MgSi}_{2} \mathrm{O}_{7}$ crystals, $d_{14}$ is decreased from 5.3 $\mathrm{pC} / \mathrm{N}$ to $1.7 \mathrm{pC} / \mathrm{N}$ with temperature increasing from $25^{\circ} \mathrm{C}$ to $500^{\circ} \mathrm{C}$. The bond lengths of $\mathrm{Ca}-\mathrm{O}$ were reported to increase with increasing temperature, with different variation levels for different $\mathrm{Ca}-\mathrm{O}$ bonds, ${ }^{26}$ leading to a certain degree of tilt for $\mathrm{CaO}_{8}$ antiprisms, which may account for the decreased $d_{14}$. Piezoelectric coefficient $d_{36}$ was found to decrease prior to the incommensurate-normal phase transition point $T_{i c-N}$, above which, it is increased. This can be explained by the distortion/rotation of the tetrahedral layers. In the structure of $\mathrm{Ca}_{2} \mathrm{MgSi}_{2} \mathrm{O}_{7}$, the mean $\mathrm{Ca}-\mathrm{O}$ bond length of $2.568 \AA$ is larger than the typical $\mathrm{Ca}-\mathrm{O}$ bond length of $2.500 \AA$ calculated by ionic radii at room temperature. The trend to form adequate interstices for the $\mathrm{Ca}$-ions is believed to be the driving force of the distortion/rotation of tetrahedrons. ${ }^{19}$ Thus, the longer bond length of $\mathrm{Ca}-\mathrm{O}$, the larger the distortion/rotation of tetrahedrons, giving rise to larger $d_{36}$ value. It should be noted that some of the $\mathrm{Ca}-\mathrm{O}$ bond lengths in $\mathrm{Ca}_{2} \mathrm{MgSi}_{2} \mathrm{O}_{7}$ are decreased from room temperature to $T_{I c-N},{ }^{26}$ leading to the decreased $d_{36}$ value. Above $T_{I c-N}$, all the Ca-O lengths are increased with temperature, ${ }^{26}$ thus $d_{36}$ is increased slightly from 87 to $500^{\circ} \mathrm{C}$.

\section{CONCLUSIONS}

$\mathrm{Ca}_{2} \mathrm{Ga}_{2} \mathrm{SiO}_{7}, \mathrm{Ca}_{2} \mathrm{MgSi}_{2} \mathrm{O}_{7}$, and $\mathrm{CaNdGa}_{3} \mathrm{O}_{7}$ single crystals with melilite structure were grown by the Czochralski method. Thermal properties, including thermal expansion and specific heat, were investigated. Full matrices of electromechanical constants of these melilite crystals were 
measured by the impedance method with $d_{14}$ being on the order of 5.3-9.3 pC/N. The relationship between microstructure and electromechanical properties of $\mathrm{CNG}, \mathrm{CGS}$, and CMS was established, which will benefit the exploration of the piezoelectric origin in melilite crystals. The distortion of eight-fold antiprisms and the distortion/rotation of tetrahedrons contribute to the piezoelectric coefficients $d_{14}$ and $d_{36}$, respectively. In addition, the tetrahedral layers act as barriers against charge transport, leading to the highest resistivity in $\mathrm{Z}$-cut $\mathrm{Ca}_{2} \mathrm{MgSi}_{2} \mathrm{O}_{7}$ crystals, while a high disorder level induces phonon scattering and decreases the electrical resistivity, accounting for the degraded resistivity in $\mathrm{CaNdGa}_{3} \mathrm{O}_{7}$ crystals. The temperature dependence of properties was investigated, where the elastic constants showing a high thermal stability over the temperature of $25-500{ }^{\circ} \mathrm{C}$ with minimal variation of $6 \%$.

\section{ACKNOWLEDGMENTS}

The authors would like to thank Professor Thomas R. Shrout for his helpful discussion. The authors from Shandong University acknowledged the National Natural Science Foundation of China (Grant No. 51372189).

${ }^{1}$ W. A. Deer, R. A. Howie, and J. Zussman, An Introduction to the RockForming Minerals, 2nd ed. (Longman, London, 1992).

${ }^{2}$ M. Merlin, M. Gemmi, and G. Artioli, Phys. Chem. Miner. 32, 189 (2005).

${ }^{3}$ A. Sugimoto, Y. Nobe, T. Yamazaki, Y. Anzai, K. Yamagishi, Y. Segawa, and H. Takei, Phys. Chem. Miner. 24, 326 (1997).

${ }^{4}$ A. A. Kaminskii, L. Bohatý, P. Becker, J. Liebertz, P. Held, H. J. Eichler, H. Rhee, and J. Hanuza, Laser Phys. Lett. 5, 845 (2008).
${ }^{5}$ Y. I. Sigalovskaya, Y. Z. Nozik, and A. B. Tovbis, Kristallografiya 34, 316 (1989).

${ }^{6}$ S. F. Bartram, Acta Crystallogr., Sect. B 25, 791 (1967).

${ }^{7}$ B. E. Warren, Z. Kristallogr. 74, 131 (1930).

${ }^{8}$ J. V. Smith, Am. Mineral. 38, 643 (1953).

${ }^{9}$ L. Bindi, P. Bonazzi, M. Dusek, V. Petricek, and G. Chapuis, Acta Crystallogr., Sect. B 57, 739 (2001).

${ }^{10}$ L. Bohatý and J. Liebertz, Z. Kristallogr. 159, 277 (1982).

${ }^{11}$ H. Takeda, M. Hagiwara, H. Noguchi, T. Hoshina, and T. Takahashi, Appl. Phys. Lett. 102, 242907 (2013).

${ }^{12}$ M. Hiroaki, H. Noguchi, T. Hoshina, H. Takeda, S. Fujihara, N. Kodama, and T. Tsurumi, Jpn. J. Appl. Phys. Part 1 52, 09KD03 (2013).

${ }^{13}$ Y. Y. Zhang, X. Yin, H. H. Yu, H. J. Cong, H. J. Zhang, J. Y. Wang, and R. I. Boughton, Cryst. Growth Des. 12, 622 (2011).

${ }^{14}$ C. Y. Shen, H. J. Zhang, Y. Y. Zhang, J. W. Wang, S. J. Zhang, and T. R. Shrout, in 2014 Joint IEEE International Symposium on the Applications of Ferroelectrics, International Workshop on Acoustic Transduction Materials and Devices \& Workshop on Piezoresponse Force Microscopy (ISAF/IWATMD/PFM) (IEEE, 2014), pp. 195-198.

${ }^{15}$ IEEE Standard on Piezoelectricity, ANSI/IEEE Std 176-1987, American Standards National Institute, New York, 1987.

${ }^{16}$ K. Iishi, T. Mizota, K. Fujino, and Y. Furukawa, Phys. Chem. Miner. 17, 720 (1991).

${ }^{17}$ S. L. Webb, C. R. Ross II, and J. Liebertz, Phys. Chem. Miner. 18, 522 (1992).

${ }^{18}$ C. Y. Shen, S. J. Zhang, D. L. Wang, T. X. Xu, H. H. Yu, W. W. Cao, J. Y. Wang, and H. J. Zhang, CrystEngComm 17, 1791 (2015).

${ }^{19}$ C. V. Heurck, G. V. Tendeloo, and S. Amelinckx, Phys. Chem. Miner. 18, 441 (1992).

${ }^{20}$ M. Miyayama and I. S. Yi, Ceram. Int. 26, 529 (2000).

${ }^{21}$ C. Y. Shen, H. J. Zhang, H. J. Cong, H. H. Yu, J. Y. Wang, and S. J. Zhang, J. Appl. Phys 116, 044106 (2014).

${ }^{22}$ S. J. Zhang and F. P. Yu, J. Am. Ceram. Soc. 94, 3153 (2011).

${ }^{23}$ R. D. Shannon, Acta Crystallogr., Sect. A 32, 751 (1976).

${ }^{24}$ A. G. Cockbain and P. J. Harrop, J. Phys. D 1, 1109 (1968).

${ }^{25}$ D. K. Kwon, Ph. D. dissertation, Materials Science and Engineering Department, The Pennsylvania State University, 2006.

${ }^{26}$ K. Kusaka, K. Hagiya, M. Ohmasa, Y. Okano, M. Mukai, K. Iishi, and N. Haga, Phys. Chem. Miner. 28, 150 (2001). 